\title{
Effect of Kinesiology Taping in addition to Splint Therapy on Pain, Functional Condition, and Hand Grip Strength in Patients with Carpal Tunnel Syndrome
}

\author{
Karpal Tünel Sendromlu Hastalarda Splint Tedavisine Ek Olarak Verilen \\ Kinezyolojik Bantlama Tedavisinin A $\breve{g}$ r, Fonksiyonel Durum ve El \\ Kavrama Kuvvetine Etkisi
}

Nadide Şen, Banu Ordahan, Hatice Uğurlu

Department of Physical Medicine and Rehabilitation, Meram Medical School, Necmettin Erbakan University, Konya, Turkey

\section{N. Şen \\ 0000-0002-7295-6779 \\ B. Ordahan \\ 0000-0003-2221-2728 \\ H. Uğurlu \\ 0000-0001-6728-232X}

Geliş Tarihi/Date Received: 24.09.2019

Kabul Tarihi/Date Accepted: 31.01.2020

Yayin Tarihi/Published Online: 30.05.2020

\section{Yazışma Adresi /} Corresponding Author:

Banu Ordahan

Necmettin Erbakan

Üniversitesi, Meram Tıp Fakültesi Fiziksel Tip ve Rehabilitasyon Anabilim Dall, Konya, Turkey

E-mail:

banuordahan@gmail.com

(C2020 Türkiye Spor Hekimleri Derneği. Tüm hakları saklıdır.

\section{ABSTRACT}

Objective: This study aimed to evaluate the effects of added kinesiology taping treatment on pain, functional status, and hand grip strength in patients with carpal tunnel syndrome (CTS).

Material and Methods: Eighty patients aged 18 years and over who were diagnosed with mild to moderate CTS by physical examination and electrophysiological findings were included in the study. Of these, $16(20 \%)$ were males and $64(80 \%)$ were females. Visual analogue scale (VAS), Boston KTS Questionnaire (BCTQ) and hydraulic hand dynamometer (Jamar) scores were used for the evaluation. The patients were randomly divided into two groups as splint (S) and Splint+Kinesiotape (SKT) treatment groups. Patients in the $S$ group only received a volar-assisted splint in the neutral position. The patients were asked to wear the splints, especially during the night for three weeks. The SKT group was treated with kinesiology taping in addition to splinting. The taping process was repeated by the same person twice a week for three weeks.

Results: The mean age of the patients was $47.0 \pm 11.4$ for the $S$ group and $50.2 \pm 11.9$ for the SKT group. In both groups, VAS, BCTQ-symptom severity scale (SSS), functional capacity scale (FDS), and hand dynamometer (kgf) measurements were statistically significant at three weeks post-treatment $(p<0.01)$. No statistically significant differences were found between the groups in terms of VAS, BCTQ-SSS, BCTQ-FDS and hand dynamometer scores ( $p>0.05)$.

Conclusion: In the conservative treatment of CTS, splint therapy has been shown to have a positive effect on VAS, BCTQ-SSS, BCTQ-FDS, and hand muscle strength. The superiority of splint therapy with kinesio taping, over splint therapy alone could not be demonstrated in the short-term.

Keywords: Carpal tunnel syndrome, hand grip strength, splint, kinesiology taping

\section{öz}

Amaç: Bu çalışmada karpal tünel sendromu (KTS) hastalarında kinezyolojik bantlama tedavisinin ağrı, fonksiyonel durum ve el kavrama kuvveti üzerine etkisinin değerlendirilmesi amaçlandı.

Gereç ve Yöntemler: Fizik muayene ve elektrofizyolojik bulgularla hafif ve orta şiddette KTS tanısı konulmuş 18 yaş ve üzeri 80 hasta çalışmaya alındı. Hastaların 16 'sı (\%20) erkek, 64'ü (\%80) kadındı. Değerlendirmede vizüel analog skala (VAS), Boston KTS Anketi (BCTQ) ve hidrolik el dinamometresi (Jamar) kullanıldı. Hastalar splint (S) ve splint + kinezyolojik bantlama (SKB) tedavi grupları olarak rastgele iki 
gruba ayrıldı. Sadece S grubundaki hastalara nötral pozisyonda ve volar destekli bir splint uygulandı. Hastalardan splintleri üç hafta boyunca özellikle geceleri sürekli ve gündüz mümkün olduğunca kullanmaları istendi. SKB grubuna ise splinte ek olarak kinezyolojik bantlama tedavisi uygulandı. Bantlama işlemi aynı kişi tarafından haftada iki kez üç hafta boyunca tekrarlandı.

Bulgular: Hastaların yaş ortalaması $S$ grubu için $47.0 \pm 11.4$, SKB grubu için $50.2 \pm 11.9$ idi. Her iki grupta tedavi öncesiyle kıyaslandığında, tedavi sonrası 3. haftada VAS, BCTQ-semptom şiddet skalası (SSS), BCTQ-fonksiyonel kapasite skalası (FDS) ve el dinamometresi (kgf) ölçümlerinde istatistiksel anlamlı düzelme saptandı $(p<0.01)$. Tedavi öncesiyle kıyaslandığında VAS, BCTQ-SSS, BCTQ-FDS ve el dinamometresi ölçümleri bakımından gruplar arasında istatistiksel anlamlı farklılık belirlenmedi ( $\left.p^{>} 0.05\right)$.

Sonuç: KTS'nin konservatif tedavisinde splint tedavisinin VAS, BCTQ-SSS, BCTQ-FDS ve el kas kuvveti üzerine olumlu etkisi gösterildi. Splint ile beraber kinezyolojik bantlama uygulamasının sadece splint ile tedaviye kıyasla kısa dönemde üstünlüğü gösterilemedi.

Anahtar sözcükler: Karpal tünel sendromu, el kavrama kuvveti, splint, kinezyolojik bantlama

Available at: http://journalofsportsmedicine.org and http://dx.doi.org/10.5152/tjsm.2020.183

Cite this article as: Sen N, Ordahan B, Ugurlu $\mathrm{H}$. Effect of kinesiology taping in addition to splint therapy on pain, functional condition, and hand grip strength in patients with carpal tunnel syndrome. Turk J Sports Med. 2020;55(4):267-75.

\section{GİRIS}

Karpal tünel sendromu (KTS), median sinirin karpal tünel içinde sıkışmasıdır. Median sinirin tuzaklanması en sık görülen periferik sinir tuzak nöropatisi ve periferik nöropati çeşididir (1). Median sinir el bileğinde karpal tünelin içinden geçer ve en sık bu seviyede sıkışır. Dokuz adet fleksör tendon, median sinir ve sinovyal zarlar bu tünelin içinden birlikte geçmektedir (2).

KTS için en önemli yakınma elin 1., 2. ve 3. parmağında ağrı ve parestezidir. Yakınmalar daha çok geceleri artış gösterir. Motor etkilenme durumunda tenar atrofi gelişebilir. KTS tanısı klinik ve kliniği destekleyen elektrofizyolojik bulgularla \%90'lara ulaşan doğrulukta konulabilmektedir. Ultrasonografik değerlendirmeler oldukça güncel tanı yöntemleri arasındadır. Tedavide konservatif ve cerrahi teknikler kullanılmaktadır (2-5). Konservatif tekniklerden olan splintler birinci basamak tedavi olarak uygulanmaktadır. El bileğini nötral konumda tutan splint farklı açılardaki splintlerden daha etkili bulunmuştur $(2,3)$. Kinezyolojik bantlama teknikleri son dönemlerde konservatif teknikler arasında sayılmaktadır. KTS tedavisinde uygulanan nöral teknik ve alan düzeltme tekniği ile karpal ligament enine uzatılarak median sinir üzerindeki basınç önemli ölçüde azaltılır. Derinin kaldırılması ile kan dolașımını engelleyen lenfatik ödem azaltılır, tendonların ve fasyaların hareketi kolaylaşır ve ağrıya neden olan baskı azaltılır (6-8).

KTS hastalarında splint tedavisi ilk seçenek yöntemlerden olmasına karşın tedavi etkinliği ve semptomları azaltması açısından yetersiz kalabilmektedir. Bu randomize kontrollü çalışmada KTS hastalarında splint tedavisine ek olarak verilen kinezyolojik bantlama tedavisinin, sadece splint tedavisine göre ağrl, fonksiyonel durum ve el kavrama kuvveti üzerine olası yararlı etkisinin değerlendirilmesi amaçlandı.

\section{GEREC ve YÖNTEMLER}

Çalışmaya Necmettin Erbakan Üniversitesi Meram Tıp Fakültesi Hastanesi Fiziksel Tıp ve Rehabilitasyon polikliniklerine Ocak-Nisan 2019 tarihleri arasında başvuran, fizik muayene bulgulariyla ve elektronöromiyografi (ENMG)'de hafif ve orta şiddette KTS tanısı konulmuş 18 yaş ve üzeri 80 hasta alındı. Tüm hastalar çalışma hakkında bilgilendirildi ve bilgilendirilmiş gönüllü onam formu doldurdular. Necmettin Erbakan Üniversitesi Tıp Fakültesi Klinik Araştırmalar Etik Kurulunun 4 Ocak 2019 tarihli 2018/1654 sayılı kararı ile çalışmanın onayı alındı.

Elin ilk üç parmağında altı haftadan uzun süren noktürnal parestezi ve ağrı semptomları varlığı, Tinel, Phalen ve ters Phalen testlerinden en az birinin pozitif olması, ENMG ile KTS tanısı ko- 
nulmuş hastalar çalışmaya alındı. Diabetes mellitus, akut travma, nörolojik hastalıklar, hamilelik, hipotiroidizm ve hipertiroidizm gibi faktörleri bulunan, önceki ay içinde non-steroid antienflamatuar ilaçlar gibi düzenli tıbbi tedavi veya fizik tedavi programları gören, son üç ay içerisinde el bileğine steroid enjeksiyonu yapılmış olan, bileklerinde splint kullanmalarını engelleyen hareket kısitlılığı bulunan; el, el bileği ve önkol derisinde kinezyolojik bantlama tedavisine engel olabilecek döküntüleri veya açık yaraları bulunan, bilateral KTS'si olan, ENMG ile ağır KTS tanılı olan, servikal radikülopati, polinöropati, proksimal median nöropati veya ulnar nöropatisi bulunan hastalar çalışma dışı bırakıldı.

Hastaların yaş, cinsiyet, dominant el, hasta el, vücut kütle indeksi (VKİ), meslek bilgileri; semptom süreleri, elin radial tarafındaki uyuşma-karıncalanma hissi, noktürnal semptomlar, özgeçmiş, kullandığı ilaçlar, ENMG bulguları gibi bilgileri kaydedildi. Hastaların el-el bileği eklem hareket açıklığı (EHA), tenar atrofi, baş parmak abdüksiyon kas kuvveti, ilk üç parmakta duyu kusuru, Tinel testi, Phalen testi ve ters Phalen testi gibi fizik muayene bulguları da kaydedildi.

Hastalar rastgele iki gruba ayrıldı. Her grupta 40 hasta olmasına karar verildikten sonra yazı tura usulü ile randomizasyon sağlandı. S grubuna sadece splint tedavisi uygulanırken SKB grubuna splint ve kinezyolojik bantlama tedavisi uyguland. Her iki gruba median sinir ve tendon kaydırma egzersizleri açıklandı ve ev programı olarak günde iki kez uygulamaları söylendi. Egzersizlerin düzenli olarak uygulanması gerektiği, hastaya her hafta kinezyolojik bantlama tedavisi sırasında tekrar hatırlatıldı. Hastalığ aktiviteler anlatıldı ve dikkat edilmesi önerildi.

\section{Değerlendirme Parametreleri}

Değerlendirmek amaciyla VAS, BCTQ-SSS ve BCTQ-FDS ve hidrolik dinamometre (Jamar) ile el kavrama kuvveti ölçüm testi kullanıldı. Tüm değerlendirme parametreleri, çalışma başlangıcında ve üç haftalık takip sonrasında kaydedildi.

VAS: Bir ağrı değerlendirme parametresi olarak kullanıldı. Hastaların son bir hafta içinde gece boyunca (istirahatte) ve gün içinde (hareket sırasında) ağrı düzeyleri değerlendirildi. VAS'a göre " 0 " hiç ağrı/uyuşma olmadığını belirtirken, "10" tolere edilemeyecek derecede ağrı/uyuşma olduğunu belirtmektedir (9).

BCTQ: KTS'ye özgü bir anket olarak Levine et al. (10) tarafindan oluşturulmuştur. Semptom şiddet skalası (SSS) ve fonksiyonel durum skalası (FDS) olarak iki kısımdan oluşur. On bir soru SSS ve sekiz soru FDS olmak üzere toplam 19 soru içermektedir. Ağrı, hissizlik, karıncalanma, güçsüzlük semptomları SSS ile değerlendirilirken, günlük yaşam aktivitelerindeki zorlanma derecesi ve fonksiyonel kapasite FDS ile değerlendirilir. Türkçe geçerlik ve güvenilirliği daha önceden yapılan bu ankette hafif semptomlar veya en iyi fonksiyonel kapasiteye 1 puan; en ağır semptomlar veya en kötü fonksiyonel kapasiteye 5 puan verilmektedir (11). Çalışmada puanların SSS ve FDS olarak ayrı ayrı toplamları alındı.

El Kavrama Kuvveti Ölçüm Testi: Ölçümlerde hidrolik el dinamometresi (Jamar) kullanıldı (Şekil 1). Dirsek fleksiyonda ve vücuda birleşik, önkol nötral pozisyondayken üç ölçüm yapıldı. Ölçümler kgf cinsinden ortalamaları alınarak çalışma formuna kaydedildi (12).

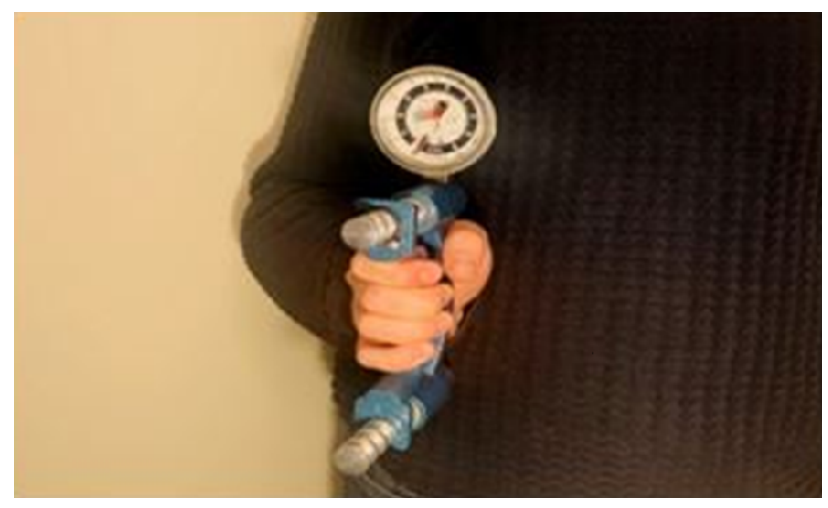

Şekil 1. Hidrolik el dinamometresi (Jamar)

\section{Tedavi Uygulamaları}

Splint tedavisi: Hastalara el bileğini nötral pozisyonda tutan volar destekli bir splint verildi. $\mathrm{Bu}$ splint el bileğinin pronasyonuna ve supinasyonuna izin verip fleksiyon, ekstansiyon, radial ve ulnar deviasyona izin vermeyecek özellikte 
hazırlandı $(13,14)$. Hastalardan splinti geceleri sürekli ve gündüz mümkün olduğunca takmaları istendi. Splintin düzenli kullanımı, haftalık olarak kinezyolojik bant uygulaması sırasında hastalara anlatıldı ve haftalık olarak takip edildi. Tedavi üç hafta süre ile her iki gruba da uygulandı.

Kinezyolojik bantlama tedavisi: Tedavi öncesinde bant uygulanacak bölgenin uygun cilt temizliği yapılması istendi. El-el bileği volar yüzünde kıl olan hastaların bunları tıraş etmeleri, krem ya da benzeri maddeleri kullanmamaları ve cildin kuru olması istendi. Uygulama tekniği olarak nöral ve alan düzeltme teknikleri birlikte uygulandı. Malzeme olarak çeșitli renklerde kinezyobant (Kinesio Tex Gold) kullanıldı. Hastanın birinci karpometakarpal eklemi ile lateral epikondilin $5 \mathrm{~cm}$ altı arası uzunluğunda, $2.5 \mathrm{~cm}$ eninde iki adet I bant ve el bileği çevresinin yarısı uzunluğunda $5 \mathrm{~cm}$ eninde bir adet I bant kullanıldı. El bileği $30^{\circ}$ ekstansiyon, ön kol supinasyon, dirsek ekstansiyonda iken uygulama yapıldı. Median sinir için ikinci ve üçüncü metakarp ortasından lateral epikondilin $5 \mathrm{~cm}$ altına kadar tüm sinir boyunca $\% 50$ gerim yapılarak, bandın son 3 cm'lik bölümü germe yapmadan yapıştırıldı.

Aynı işlem ulnar sinir için dördüncü ve beşinci metakarp ortasından medial epikondilin $5 \mathrm{~cm}$ altına kadar uygulandı. El bileği volar yüzeyine I bandın ortadaki $1 / 3$ 'lük bölümüne $\% 50$ gerim uygulanarak ve iki taraftaki uçlara germe uygulamadan yapıștırıldı (Şekil 2). Bantlama işlemi aynı kişi tarafından haftada iki kez, üç hafta boyunca tekrarlandı. Hastalar haftanın her günü kinezyolojik bantlı durumda idi. Tedavi süresince hastalara; aşırı terlemeye neden olabilecek faaliyetlerde bulunmamaları ve aşırı suya maruz kalınmaması gerektiği konusunda bilgi verildi. Bantta ayrılma yırtılma gibi sorunlar oluşması durumunda bant yenilendi. Tüm değerlendirme parametreleri aynı kişi tarafından uygulandı. $\mathrm{Bu}$ tedavi SKB grubuna uygulandı (7).

\section{İstatistiksel Analiz}

SPSS v25.0 (IBM SPSS Statistics for Windows, version 25.0, released 2017; IBM Co., Armonk, NY, USA) paket programı kullanılarak yapıldı. Değişkenler ortalama, standart sapma, maksi- mum, minimum, yüzde ve frekans değerleri ile ifade edildi. Verilerin tekrarlanan ölçümler varyans analizine uygunluğu Mauchy's küresellik testi ve Box-M varyansların homojenliği testi ile değerlendirildi. Ortalamaların karşılaştırmaları için faktöriyel düzende faktörlerden biri tekrarlanan ölçümler varyans analizi kullanıldı. Çoklu karşılaştırmalar ise düzeltilmiş Bonferroni testi ile gerçekleştirildi. Değişkenler normallik, varyansların homojenliği ön şartlarının kontrolü Shapiro-Wilk ve Levene testleriyle yapıldıktan sonra değerlendirildi. Veri analizi yapılırken, iki grup karşılaştırması için bağımsız iki grup t testi (Student's $t$ test) kullanıldı. Bağımlı iki grup karşılaştırması yapılırken eşleşmiş $t$ testi kullanıldı. Kategorik veriler Fisher's exact test ve ki kare testi ile analiz edildi. Beklenen frekansların $\% 20$ 'den küçük olduğu durumlarda bu frekansların analize dahil edilmesi için "Monte Carlo simülasyon yöntemi" ile değerlendirme yapıldı. Sosyodemografik veriler için anlamlılık düzeyi $\mathrm{p}<0.05$ ve VAS, BCTQ-SSS ve BCTQ-FDS ve el kavrama kuvveti verileri için $\mathrm{p}<0.01$ değeri anlamlı kabul edildi.

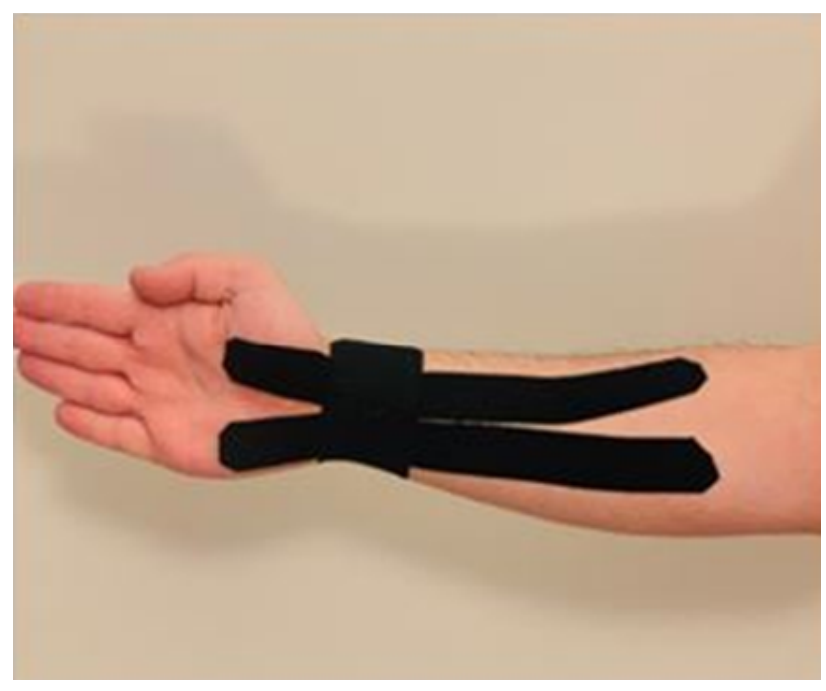

Şekil 2. Kinezyobantlama uygulaması

\section{BULGULAR}

Çalışmaya alınan 80 KTS hastasının 16'sı (\%20) erkek, 64'ü (\%80) kadındı. Hastaların yaş orta-

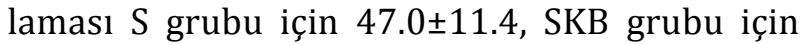
$50.2 \pm 11.9$ idi. Hastaların fiziksel ve mesleki veri- 
leri Tablo 1'de; klinik ve fizik muayene verileri ise Tablo 2'de verilmektedir.

Her iki grup için VAS, BCTQ-SSS, BCTQ-FDS ve el dinamometresi ölçümleri bakımından 0 . ve 3 . haftalarda anlamlı düzelme saptanırken gruplar arasında anlamlı fark gözlenmedi ( $p>0.05)$ (Tablo 3).

Tablo 1. Hastaların fiziksel ve meslek verileri

\begin{tabular}{|c|c|c|c|c|}
\hline & & S grubu & SKB grubu & Toplam \\
\hline & Yaş (yıl) & $47.0 \pm 11.4$ & $50.2 \pm 11.9$ & \\
\hline & \multirow{2}{*}{ Cinsiyet (E/K) } & $10(62.5)$ & $6(37.5)$ & $16(20)$ \\
\hline & & $30(46.9)$ & $34(53.1)$ & $64(80)$ \\
\hline & \multirow{2}{*}{ Dominant el } & $37(50.0)$ & $37(50.0)$ & $74(92)$ \\
\hline & & $3(50.0)$ & $3(50.0)$ & $6(08)$ \\
\hline & \multirow{2}{*}{ Etkilenmiş el } & $25(49.0)$ & $26(51.0)$ & $51(63)$ \\
\hline & & $15(51.7)$ & $14(48.3)$ & $29(37)$ \\
\hline \multirow{3}{*}{ 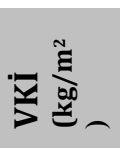 } & $\mathrm{N}$ & $3(60.0)$ & $2(40.0)$ & $5(06)$ \\
\hline & $P$ & $10(38.5)$ & $16(61.5)$ & $26(32)$ \\
\hline & 0 & $27(55.1)$ & $22(44.9)$ & $49(68)$ \\
\hline \multirow{5}{*}{$\frac{y}{\frac{d}{d}}$} & Ev hanımı & $24(45.3)$ & $29(54.7)$ & $53(66)$ \\
\hline & Bilgisayar operatörü & $1(50.0)$ & $1(50.0)$ & $2(03)$ \\
\hline & El gücü ile çalışan & $13(81.3)$ & $3(18.7)$ & $16(20)$ \\
\hline & Emekli & $2(40.0)$ & $3(60.0)$ & $5(06)$ \\
\hline & Öğretmen & $0(00.0)$ & $4(100)$ & $4(05)$ \\
\hline
\end{tabular}

Tablo 2. Hastaların klinik ve fizik muayene özellikleri

\begin{tabular}{lllll}
\hline Özellik & Bulgu & S grubu & SKB grubu & Toplam \\
\hline \multirow{2}{*}{ Semptom Süresi } & $3-12$ ay & $27(55.1)$ & $22(44.9)$ & $49(61)$ \\
Parestezi & $>12$ ay & $13(41.9)$ & $18(58.1)$ & $31(39)$ \\
\multirow{2}{*}{ Güçsüzlük Hissi } & Yok & $1(50.0)$ & $1(50.0)$ & $2(03)$ \\
& Var & $39(50.0)$ & $39(50.0)$ & $78(97)$ \\
Noktürnal Semptom & Yok & $11(55.0)$ & $9(45.0)$ & $20(25)$ \\
& Var & $29(48.3)$ & $31(51.7)$ & $60(75)$ \\
ENMG Bulguları & Yok & $3(60.0)$ & $2(40.0)$ & $5(06)$ \\
Tinel Testi & Var & $37(49.3)$ & $38(50.7)$ & $75(94)$ \\
Phalen Testi & Hafif KTS & $5(33.3)$ & $10(66.7)$ & $15(18)$ \\
Ters Phalen T. & Orta KTS & $35(53.8)$ & $30(46.2)$ & $65(82)$ \\
& - & $4(33.3)$ & $8(66.7)$ & $12(15)$ \\
\hline
\end{tabular}


Tablo 3. VAS. BCTQ-SSS. BCTQ-FDS ve el dinamometresi ölçümlerinin grup ve haftalara göre değerlendirilmesi

\begin{tabular}{|c|c|c|c|c|c|c|}
\hline Test & & $S(n=40)$ & p (grup içi) & SKB $(n=40)$ & p (grup içi) & p (gruplar arası) \\
\hline \multirow{2}{*}{ VAS } & Hafta 0 & $5.08 \pm 2.63$ & \multirow{2}{*}{$0.001^{* *}$} & $5.03 \pm 2.89$ & \multirow{2}{*}{$0.001^{* *}$} & 0.940 \\
\hline & Hafta 3 & $2.30 \pm 2.28$ & & $1.80 \pm 2.24$ & & 0.330 \\
\hline \multirow{2}{*}{ BCTQ-SSS } & Hafta 0 & $30.6 \pm 8.4$ & \multirow{2}{*}{$0.001^{* *}$} & $30.1 \pm 7.0$ & \multirow{2}{*}{$0.001^{* *}$} & 0.760 \\
\hline & Hafta 3 & $21.0 \pm 6.8$ & & $18.4 \pm 6.4$ & & 0.080 \\
\hline \multirow{2}{*}{ BCTQ-FDS } & Hafta 0 & $20.1 \pm 6.4$ & \multirow{2}{*}{$0.001^{* *}$} & $22.3 \pm 6.1$ & \multirow{2}{*}{$0.001^{* *}$} & 0.130 \\
\hline & Hafta 3 & $15.4 \pm 5.4$ & & $16.2 \pm 5.3$ & & 0.500 \\
\hline \multirow{2}{*}{ El kuvveti (kgf) } & Hafta 0 & $21.0 \pm 7.0$ & \multirow{2}{*}{$0.001^{* *}$} & $19.7 \pm 7.1$ & \multirow{2}{*}{$0.001^{* *}$} & 0.400 \\
\hline & Hafta 3 & $22.6 \pm 7.4$ & & & & 0.670 \\
\hline
\end{tabular}

**: $p<0.01$; Değerler X \pm SD; VAS: vizüel analog Skala, BCTQ-SSS: Boston karpal tünel sendromu anketi-semptom şiddet skalasl; BCTQ-FDS: BCTQ-fonksiyonel kapasite skalası

\section{TARTIȘMA}

Splint tedavisi, KTS'de ilk tercih edilen yöntemlerdendir (15). Nötral açıda splintlemenin amacı tünel hacminin arttırılması ve sinir üzerindeki baskının azaltılmasıdır (16). Splintlemenin KTS semptomlarını azaltmada etkili olduğu düşünülmektedir ve hafif semptomatik hastalarda cerrahi gereksinimini geciktirebilmekte veya ortadan kaldurabilmektedir (13,17-19). Yakınmaların başlamasından itibaren ilk üç ay içinde splint uygulamasının semptomları azaltmada daha iyi olduğu gösterilmiștir (20). Semptomların kısa sürmesi ve noktürnal semptomların az olması splint tedavisinin uzun dönemdeki yararını destekleyen özelliklerdir (21).

Splintlerin gün içinde kullanım periyotları ile ilgili farklı öneriler vardır. Noktürnal semptomları fazla olan hastalarda splintlerin diğer tedavilerin yanında özellikle geceleri de kullanımı önerilmiştir (16). Splintin gece boyunca ve mümkün olduğunca gündüz takılması gerektiğini gösteren çalışmalar bulunmaktadır (22). Bunun yanı sıra bu kullanım şeklinin stres oluşturabileceğini ve tedavi etkinliğini düşüreceğini gösteren çalışmalar da vardır (23). Splintin sadece gece kullanılmasını öneren çalışmalar olmakla birlikte, son çalışmalarda gün boyu splint kullanmanın etkin bir tedavi olabileceği gösterilmiștir $(1,13,24)$. Bu farklı görüșler özellikle hasta seçimindeki farklılıklardan kaynaklanmaktadır. Çalışmamızda hastalara geceleri sü- rekli, gündüzleri de olabildiğince splinti kullanmaları önerisinde bulunuldu.

Literatürde, KTS tedavisinde splint uygulamasının etkinliği konusu tartışmalıdır. Kullanılan splint pozisyonları açısından tutarlılık yoktur. El bileğinin nötr pozisyonda splintlenmesi ile 105 hastanın sadece \%67'sinde semptomların azaldığı gösterilmiștir (22). Başka bir çalışmada altı hafta splint kullanan hastalar açık karpal tünel dekompresyon ameliyatı yapılan hastalarla karşılaştırılmış ve 18 ay boyunca takipleri yapılmıştır. Splint verilen hastaların \%41'inin bu dönemde KTS ameliyatı geçirmiștir. Ayrıca, takip süresinde ameliyat geçiren hastalar, splintlenmiş hastalara göre anlamlı düzelme göstermişlerdir (18). Bir diğer çalışmada da dört hafta boyunca splint uygulanan hastaların BCTQ skorlarında dört hafta sonra kontrol grubuna göre istatistiksel olarak anlamlı bir iyileșme gözlenmiştir (25). KTS'de parafin tedavisinin etkinliğinin araştırıldığı bir çalışmada üç hafta boyunca bir gruba splint, diğer gruba splint ve parafin tedavisi verilmiștir. Sadece splint grubunda VAS ve BCTQ-SSS ölçümlerinde anlamlı düzelme olurken, BCTQ-FDS ölçümlerinde bu gözlenmemiştir (3). Splintlemenin altı ayda tek doz glükokortikoid enjeksiyonu ile benzer sonuçlara yol açtığı, ancak iyileşmenin biraz daha uzun sürebildiği ifade edilmiştir (26).

Kinezyobant, spor yaralanmaları ve diğer çeşitli rahatsızlıkları tedavi etmek için kullanılan elas- 
tik terapötik bir banttır (27). KB ile deri bir miktar kalkar, cilt altı alan arttığı için dolaşım ve hareket rahatlamış olur. Dolaşımın artması ile enflamasyon azalır. $\mathrm{Bu}$ şekilde ağrının azaltılması, hasarın önlenmesi ve doku iyileşmesi amaçlanır (28). KB yönteminin kas kvvetini ve propriosepsiyonu arttırıcı etkisi net değildir. Yirmi bir sağlıklı sporcuda yapılan bir çalışmada ön kolun KB uygulaması propriosepsiyon ve el kavramada kısa süreli iyileşme sağlamış, ancak uzun vadede etkisi gösterilememiştir (29).

Öncü ve ark.nın çalışmasında 60 KTS'li hasta el randomize olarak dört gruba ayrılmıştır: Salt $S$ veya $\mathrm{KB}$, kombine SKB ve kontrol grupları. Hastalar tedavi öncesinde, tedavi sonunda 25. günde, tedavi sonrası 2. ve 3. aylarda BCTQ-SSS ve FDS, kaba kavrama, parmak ucu kavrama ve el beceri testleri ile değerlendirilmiştir. Tedavi öncesi ve üçüncü ay sonunda elektrofizyolojik değerlendirilmeler yapılmıştır. SKB grubunda tüm testlerde tedavi sonu, 2 . ve 3. aylarda diğer gruplara göre anlaml klinik iyileşme saptanmıştır. Sadece KB uygulanan grupta BCTQSSS ve kaba kavramada tedavi sonu ve ikinci ayda ancak kontrol grubuna göre anlamlı iyileşme olmuştur. Tek başına splint kullanan grupta ise ikinci ayda BCTQ-SSS, -FDS ve kaba kavramada görülen iyileșme sadece kontrol grubundan üstün bulunmuştur. Sonuçta SKB kombinasyonu diğer gruplardan daha üstün ve uzun iyileşme sağlamış; tedavi öncesi ve sonrası duyusal ileti hızı hariç ENMG bulguları için gruplar arasında anlamlı farklılık bulunmamıştır (30). Bu çalıșmada KB yöntemi olarak nöral teknik ve alan düzeltme teknikleri kullanılmıştır. Biz de aynı teknikleri uygulamamıza rağmen SKB kombinasyonunun kısa dönemde salt $S$ tedavisine üstünlüğünü gösteremedik. Öncü ve ark.nın (30) tedavi öncesi ENMG değerlendirmesinde, SKB kombinasyonu ve KB gruplarında, yani KB tedavisi alan erken KTS'li hastalarm duyusal ileti hızı diğer gruplara göre daha iyi bulunmuştu. Çalışmamızdaki farklılığın her iki grupta da orta evre KTS hastalarının, erken evre olanlardan sayıca üstünlüğünden kaynaklanabileceğini ve KB uygulamasının orta evre KTS hastalarında, erken evredekiler kadar etkili olmadığını düşünmekteyiz.
Aktürk ve ark.nın çalışmalarında 58 hasta el iki gruba ayrılmıștır; KB ile egzersiz ve splint ile egzersiz grupları. Bantlama tekniği olarak nöral ve inhibisyon teknikleri kullanılmıștır. Altı haftalık tedavi ve takip öncesi ve sonrası elektrofizyolojik değişiklikler, provokatif test yanıtları, BCTQ-SSS ve -FDS skorlarinda KB grubunda S grubuna göre anlamlı iyileşmeler gözlenmiștir. KB tedavisinin özellikle erken KTS'de tercih edilmesi gerektiği vurgulanmıştır (8). Sonuçlarımızın farklı olmasının bir nedeninin kinezyolojik bantlama tekniğinin farklılığı ve hasta grubumuzun daha çok orta evre KTS hastalarını içermesi olarak açlklanabilir.

Geler Külcü ve ark.nın (31) çalışmalarında 60 KTS'li el üç gruba ayrılmıştır; KB, plasebo KB ve $S$. Tüm gruplarda dört haftalık tedavi sonrasinda nöropatik ağrı anketi, VAS ve BCTQ-SSS parametrelerinde istatistiksel olarak anlamlı düzelme gerçekleşmiştir. El kavrama kuvveti sadece splint grubunda anlamlı olarak düzelmiştir. BCTQ-FDS'de sadece KB grubunda anlamlı düzelme olmuştur. Sonuç olarak sadece KB grubunda BCTQ değerlerinde anlamlı olarak düzelme saptanırken kas kuvvetinde anlamlı farklılık belirlenmemiştir.

Yıldırım ve ark. (32) 38 KTS hastasını egzersiz ile birlikte KB ve egzersiz grubu olarak iki gruba ayırmışlar; her iki gruba tendon ve sinir kaydırma egzersizleri uygulamışlardır. KB grubuna beş günde üç kez bant uygulaması yapılmıștır. Değerlendirme parametreleri olarak BCTQ-SSS ve -FDS, el beceri testi, kavrama kuvveti, parmak ucu kavrama ve ultrasonografi ile median sinirin kesit alanı ölçülmüştür. Parametreler tedavi öncesi, 3. ve 6. haftada kaydedilmiştir. KB grubunda üçüncü haftada tüm parametrelerde anlamlı düzelme saptanmıştır. Salt egzersiz grubunda üçüncü haftada kavrama kuvveti ve median sinir kesit alanı dışındaki parametrelerde istatistiksel olarak anlamlı düzelme gözlenmiştir. Tendon ve sinir kaydırma egzersizleri ile KB tedavisi karşılaştırıldığında kısa dönemde KB yönünde anlamlı farklılık saptanırken, uzun dönemde gruplar arasında anlamlı farklılık bulunmamıştır (32).

Literatürdeki çalışmaların önemli kısmında kinezyolojik bantlama tedavisinin erken KTS'li 
hastalarda anlamlı üstünlüğü saptanmıștır. $\mathrm{Bu}$ çalışmada kinezyolojik bantlama tedavisinin splint tedavisine üstünlüğü belirlenmedi. Sonuçlardaki bu farklılığın, çalışmamızda orta dönem KTS hastalarının erken KTS hastalarına göre sayıca fazla olması, hasta uyumu, çalışmaya alınan etkilenen el-dominant el durumu, meslek, kinezyolojik bantlama teknik ve uygulama süresi gibi faktörlerin çeşitliliğinden kaynaklanabileceği düşünüldü.

Çalışmanın bazı kısıtlılıkları bulunmaktadır. Bunlar arasında tedavi ve takip süresinin kısa olması, tedavi sonrasında elektrofizyolojik parametrelere bakılmamış olması sayılabilir.

Sonuç olarak, her iki grupta da ağrı, semptom şiddet skoru, fonksiyonel kapasite skoru ve el kavrama kuvveti parametrelerinde üç haftalık tedavi sonrasinda istatistiksel olarak anlamlı düzelme saptanmıştır. Ancak tedavi sonrasında gruplar birbiri ile karşılaştırıldığında anlamlı bir farklılık belirlenememiștir.

\section{Çıkar Çatışması ve Finansal Destek}

$\mathrm{Bu}$ çalışmada herhangi bir çıkar veya finansal çıkar çatışması yoktur.

\section{KAYNAKLAR}

1. Karakoyun A, Çalık Y. Üst ekstremite tuzak nöropatileri. Ege Tıp Bil Derg. 2019;2(1):42-7.

2. Akarırmak Ü. Tuzak Nöropatileri. Beyazova M, Kutsal YG, Eds. Fiziksel Tıp ve Rehabilitasyon. 2. Baskl, Ankara: Güneş Kitabevi; 2011, pp 2995-3014.

3. Ordahan B, Karahan AY. Efficacy of paraffin wax bath for carpal tunnel syndrome: a randomized comparative study. Int $J$ Biometeorol. 2017;61(12):2175-81.

4. Karahan AY, Arslan S, Özen KE, et al. Türk toplumunda median ve ulnar sinirlerin ultrasonografik değerlendirilmesi ve antropometrik ölçümlerle ilişkisi. Ege Tıp Bil Derg. 2018;1(1):13-8.

5. Karahan AY, Arslan S, Ordahan B, et al. Superb microvascular imaging of the median nerve in carpal tunnel syndrome: an electrodiagnostic and ultrasonographic study. J Ultrasound Med. 2018;37(12):2855-61.

6. Zinnuroğlu M. Kinezyobantlama tarihçesi, kullanım alanları ve literatür bilgileri eşliğinde kas iskelet sistem problemlerinde etkinliği. Borman $\mathrm{P}$, Zinnuroğlu M, Eds. Kas-iskelet Sistemi Sorunlarında Kinezyobantlama. Ankara: Türkiye Klinikleri; 2017, pp. 1-12.
7. Güven Z. El ve el bileği ağrılarında kinezyobantlama. Borman P, Zinnuroğlu M, Eds. Kas-İskelet Sistemi Sorunlarında Kinezyobantlama. Ankara: Türkiye Klinikleri; 2017, pp. 41-4.

8. Aktürk S, Büyükavcı R, Aslan Ö, et al. Comparison of splinting and Kinesio taping in the treatment of carpal tunnel syndrome: a prospective randomized study. Clin Rheumatol. 2018;37(9):2465-9.

9. Ritter PL, González VM, Laurent DD, et al. Measurement of pain using the visual numeric scale. $J$ Rheumatol. 2006;33(3):574-80.

10. Levine DW, Simmons BP, Koris MJ, et al. A selfadministered questionnaire for the assessment of severity of symptoms and functional status in carpal tunnel syndrome. $J$ Bone Joint Surg Am. 1993;75(11):1585-92.

11. Heybeli N, Kutluhan S, Demirci S, et al. Assessment of outcome of carpal tunnel syndrome: a comparison of electrophysiological findings and a self-administered Boston questionnaire. $J$ Hand Surg $\mathrm{Br}$. 2002;27(3):259-64.

12. Massy-Westropp NM, Gill TK, Taylor AW, et al. Hand grip strength: age and gender stratified normative data in a population-based study. BMC Res Notes. 2011;4:127.

13. Walker WC, Metzler M, Cifu DX, et al. Neutral wrist splinting in carpal tunnel syndrome: a comparison of night-only versus full-time wear instructions. Arch Phys Med Rehabil. 2000;81(4): 424-9.

14. Gravlee JR, Van Durme DJ. Braces and splints for musculoskeletal conditions. Am Fam Physician. 2007;75(3):342-8.

15. Çakırbay H. Periferik sinir lezyonları. Oğuz $H$, Çakırbay H, Yanık B, Eds. Tıbbi Rehabilitasyon. 3. Baskı, Nobel Tıp Kitabevi: İstanbul; 2015, pp. 505-32.

16. Carlson H, Colbert A, Frydl J, et al. Current options for nonsurgical management of carpal tunnel syndrome. Int J Clin Rheumtol. 2010;5(1):129-42.

17. Akalin E, El Ö, Peker Ö, et al. Treatment of carpal tunnel syndrome with nerve and tendon gliding exercises. Am J Phys Med Rehabil. 2002;81(2):108-13.

18. Gerritsen AA, de Vet HC, Scholten RJ, et al. Splinting vs surgery in the treatment of carpal tunnel syndrome: a randomized controlled trial. JAMA. 2002;288(10):1245-51.

19. McClure P. Evidence-based practice: an example related to the use of splinting in a patient with carpal tunnel syndrome. J Hand Ther. 2003;16(3):256-63.

20. Yağcı İ, Uçan H, Yılmaz L, et al. Karpal tünel sendromu tedavisinde splint, splint ile lokal steroid enjeksiyonu ve cerrahinin karşılaştırılması. Türk Fiz Tıp Rehab Derg. 2006;52(2):55-60.

21. Gerritsen AA, Korthals-de Bos IB, Laboyrie PM, et al. Splinting for carpal tunnel syndrome: prognostic indicators of success. J Neurol Neurosurg Psychiatry. 2003;74(9):1342-4. 
22. Kruger VL, Kraft GH, Deitz JC, et al. Carpal tunnel syndrome: objective measures and splint use. Arch Phys Med Rehabil. 1991;72(7):517-20.

23. Dolhanty D. Effectiveness of splinting for carpal tunnel syndrome. Can J Occup Ther. 1986;53(5): 275-80.

24. Burke DT, Burke MM, Stewart GW, et al. Splinting for carpal tunnel syndrome: in search of the optimal angle. Am J Phys Med Rehabil. 1994;75(11):1241-4.

25. Manente G, Torrieri F, Di Blasio F, et al. An innovative hand brace for carpal tunnel syndrome: a randomized controlled trial. Muscle Nerve. 2001;24(8):1020-5.

26. Chesterton LS, Blagojevic-Bucknall M, Burton C, et al. The clinical and cost-effectiveness of corticosteroid injection versus night splints for carpal tunnel syndrome (INSTINCTS trial): an open-label, parallel group, randomised controlled trial. Lancet. 2018;392(10156):1423-33.

27. Kase K, Wallis J, Kase T. Clinical Therapeutic Applications of the Kinesio Taping Method. $2^{\text {nd }}$ ed. Tokyo: Ken Ikai Co. Ltd.; 2003.
28. Çeliker R, Güven Z, Aydoğ T, et al. Kinezyolojik bantlama tekniği ve uygulama alanları. Türk Fiz Tıp Rehab Derg. 2011;57:225-35.

29. Chang HY, Chou KY, Lin JJ, et al. Immediate effect of forearm Kinesio taping on maximal grip strength and force sense in healthy collegiate athletes. Phys Ther Sport. 2010;11(4):122-7.

30. Öncü J, İlişer $R$, Yllmaz $F K$, et al. Karpal tünel sendromu tedavisinde kinezyo bantlama tekniğinin hastalık semptomları, el fonksiyonu ve kavrama gücüne etkisi: tek kör randomize kontrollü çalışma. Türk Fiz Tıp Rehab Derg. 2014;60(Suppl. 1):543-51.

31. Geler Külcü D, Bursali C, Aktaş İ, et al. Kinesiotaping as an alternative treatment method for carpal tunnel syndrome. Turk J Med Sci. 2016;46(4):1042-9.

32. Yıldırım P, Dilek B, Şahin E, et al. Ultrasonographic and clinical evaluation of additional contribution of kinesiotaping to tendon and nerve gliding exercises in the treatment of carpal tunnel syndrome. Turk J Med Sci. 2018;48(5):925-32. 